Draft version - Final version published as: Arnoud Lagendijk \& Roos Pijpers (2012): Beyond the Regional Cradle and Policy trap: Proximity and Embedding as Development Potentialities, European Planning Studies, http://dx.doi.org/10.1080/09654313.2013.734457

\title{
Beyond the regional cradle and policy trap: proximity and embedding as development potentialities
}

Arnoud Lagendijk and Roos Pijpers

Prompted by the alleged rise of the 'knowledge economy', the nexus between knowledge and space presents one of the key fascinations in the field of economic geography and regional studies. Over the years, a lively, even frenzied debate, has emerged, yielding some consensus, but also many doubts and open questions. The debate starts with approaching the role of knowledge primarily from an 'endogenous' development perspective. This means that a city's or region's wealth is attributed, first and foremost, to its capacity to accumulate and valorise knowledge. Understanding this 'local' capacity in technical, organisational, institutional, and even socio-economic terms poses a key challenge for our thinking and inquiries. Especially in policy debates, these capacities are principally seen as generally attainable. The implication is that once basic resource conditions (such as physical infrastructure, education and business services) are met, each region is seen as capable of nurturing its own innovative capacities. As a result, a substantial part of policy making has been geared towards the shaping and circulation of regional 'self-help' practices, based on concepts such as clusters, Regional Innovation Systems, Triple Helix and the creative class.

A problem with the 'endogenous' perspective is its emphasis on factors and processes within the region (Van Reine \& Dankbaar, 2011). More specifically, it assumes that there are ubiquitous regional advantages 'out there' waiting to be grasped and promoted. These advantages are twofold. In part, they are based on spatial proximity, and the way that spatial proximity intersects with other forms of proximity such as social, cognitive, organisational and institutional (Boschma, 2005; Capello \& Faggian, 2005; Mattes, 2011), as a basis for knowledge creation and valorisation. Furthermore, they are based on local collective capacities to act, facilitated by common governance structures, complementarities between a variety of organisations (e.g., education, training, authorities, business and 'cluster' associations). The problem is that, regardless of its level of theoretical and analytical sophistication, this perspective tends to underestimate the importance of regions being parts of wider socio-economic systems. It narrows down to a 'regional competitiveness' perspective in which the region is considered the key cradle of competiveness (Cooke \& Morgan, 1998; Malecki, 1991; Martin \& Sunley, 1998).

The critique on the 'endogenous' line of thinking and the focus on 'regional competitiveness' have prompted two kinds of responses. First, many recent contributions have called for the inclusion of external relations (Wolfe \& Gertler, 2004). A prominent example is the conceptualisation of local 'buzz' versus global 'pipelines' (Maskell et al., 2006; Moodysson, 2008). In this approach, the 'pipelines' feed the region with technological, market and other information which is locally disseminated via 'buzz. However, taking on board external relations in such a way does not really get us out of the 'endogeneity 
trap', in which we attribute local performance to local characteristics and capacities. It merely presents an addendum to a model which assumes a powerful, generic 'engine' of wealth creation at the regional level.

Second, recent literature following a relational approach (Bathelt \& Gluckler, 2003; Boggs \& Rantisi, 2003) aims to go beyond the endogeneity trap. A relational approach replaces fixed mechanisms of proximity and regional interaction by a more contextual and dynamic approach. Rather than as fixed inputs into, or determinants of regional wealth, the roles played by proximity and local embedding are historically and spatially contingent. So rather than a causal force, proximity presents a potentiality. And the nature of this potentiality may vary widely across space and time. A classical Italian industrial district or London's CBD present a very different world for processes of communication, collaboration and competition than an 'ordinary' provincial town. This is not just a matter of accessibility, but also of difference in culture, conventions (Storper, 1997), and the trajectories that places have gone through (Massey, 1994; Massey, 2005).

Two lessons can be drawn from this. First, one should acknowledge that the spatial economy is, and will continue to be, spiky and heterogeneous, in which regions are deeply entangled in extensive networks of interactions and flows, often spanning the globe. The potentialities presented by 'proximities', 'embedding' and 'relational assets' heavily depend on these specific entanglements. We should avoid the 'endogeneity trap', in other words. Any universal notion of proximity or embedding is misplaced, even if split along various categories. If we observe certain local phenomena, such as clustering or agglomeration, the drivers of such phenomena may work at very different scales, and affect places in very different ways. Second, there is an important flipside to this contingency. The absence of universal mechanisms does not mean that regions cannot seek to develop collective capacities for wealth creation. Rather than to push preset buttons, the challenge is to identify appropriate regional potentialities in a world that is spatially, organisationally, and institutionally highly differentiated, while also manifesting certain powerful common mechanisms of exchange and coordination. Generic 'best practices' and ubiquitous policy and governance concepts will be of little value. Regions should draw, in particular, on self-built strategic intelligence, that is, on detailed insights into how local economic activities, supported by resource development, can improve their position in global knowledge flows and production chains. In the end, in a dynamic capitalist world, accumulating and sustaining wealth are inherently creative processes, which do not only apply to business development but also to building supportive assets and policies.

The pursuit of well-informed, creative strategies can help to avoid a second trap, bearing on policymaking. This 'policy trap' stems from the conflation of observed spatial economic regularities and strategic opportunities. Spatial economic regularities should be considered as an imprint of the 'average' way potentialities have been actualised across space over time. Strategic opportunities should target what, in a certain time and place, may lead to new forms of wealth creation, by exploring new forms of (inter-)action and creativity. Such opportunities involve combinations of capacities for which no 'averages' exist, and for which there are no set practices or scripts. Then, a compounding issue is that only those opportunities are useful for which there is scope of effective policy intervention. The 
question is how to identify and promote 'policy leverage' (i.e., those domains and ways of intervention that really help to build local capacities).

The papers in this special issue reflect on these issues using approaches that range from an analytical to a policy angle. In terms of substance, they cohere in the way they incrementally build a critical assessment of the causal mechanisms that are often said to undergird proximity, and an argument for a number of alternative conceptualisations and concomitant policy roles and actions.

Martijn Smit and Henri de Groot lend analytical support to our argument by assessing the role of local knowledge 'stocks' in the Netherlands using a large, comprehensive dataset. The paper draws on three waves of the Community Innovation Survey (each with between 10 and 15 thousands observations, covering more or less the period 1994-2004), complemented by census data of all Dutch firms. The results show that firm specific factors are key in explaining variation in innovative success of individual firms. The spatio-economic context in which the firm operates turns out to be much less relevant; in fact, business performance on average hardly benefits from (the potential for) local knowledge spillovers. Likewise, other often-presumed benefits, such as location in a major metropolitan area, levels of urbanisation, patterns of specialisation and diversity, and the type of business activity, yield statistically insignificant or even counterintuitive outcomes. For science-based firms, for instance, no benefits emerge from local knowledge stock availability. This prompts the authors, for example, to say that 'we should question the advantages of science parks' (Smit and De Groot, this issue). The paper thus vindicates the absence of spatial-economic regularities that would suggest a natural link between innovation and proximity. Yet this overall negative picture does not foreclose the possibility of creating proximity advantages in specific places (such as particular science parks). Such advantages should then be seen as part of capacity-building, rather than as automatic levers, which is a key message of this special issue.

The paper by Marina van Geenhuizen and Danny Soetanto explores the potentiality emerging from specific local circumstances. Focusing on university spin-offs for two case study areas, viz. Delft (the Netherlands), and Trondheim (Norway), their study examines the regional drivers for 'open innovation' based on a business survey. The survey questions are framed around an encompassing notion of learning networks, probing network density, the strength of relationships, and heterogeneity in partners' social background and spatial orientation. The main drivers that are found turn out to be different for the two regions. Firms in Delft build stronger relationships with partners which are more externally oriented compared to firms in Trondheim. Where firms in Delft benefit most from external relations and open innovation, firms in Trondheim rely more on internal capabilities. Nevertheless, job growth in both regions is comparable. This suggests that diverse models of open innovation exist, which all can be beneficial for the region.

To understand how strategies such as 'open innovation' are perceived and developed, an important factor is the wider regulatory and political context. As argued by Holger Schiele and Alexander Ebner, the most prominent factor is the institutional specificity of the national level. One of the shortcomings of the current debate on knowledge spillovers within and across cluster boundaries is the overemphasis on regional conditions. However, linkage formation between firms and other organizations, internal as 
well as external, heavily depends on the national business environment and regulatory regimes. To examine the significance of the national level, the authors analysed data from 228 suppliers in a German cluster, examining linkages, patterns and strategies. Most of these patterns were predominantly national, rather than regional. In light of regional development ambitions, the paper thus concludes that: 'These findings may imply that in the explored cluster agglomeration a strategic type of regional interaction is still underdeveloped' (Schiele and Ebner, this issue, p. ??). Hence 'The evolution of clusterbased learning regions is thus shaped by a delicate balance of openness and coherence, which underlines the need for an adequate structuration of external linkages' \{ibid\}. A key conclusion is that the national level shall not be ignored while trying to understand clusters.

The link between proximity and learning is further examined in a conceptual way by Geert Vissers and Ben Dankbaar. This paper starts with debunking various myths which have troubled the debate so far. One such myth concerns the magical status bestowed on tacit knowledge, and its equation with proximity. Similarly, proximity should not be seen as a core condition of fruitful face-to-face interaction or a key driver behind affinity and trust creation. In line with the observations made before, the authors claim, regions should not be conceived as natural cradles of economic development, but as units of imagination with flexible boundaries. Nurturing regional interaction as a means to wealth creation, requires the building of relational assets enhancing localised knowledge processes. These assets, in turn, can draw on local repertoires of practice -a concept preferred to the notion of 'culture'. Knowledge, in this context, is not seen as a 'stock' but as an activity conceived and pursued by particular agents. An emphasis on knowledge-as-activity means that the traditional method of 'following the knowledge' has to give way to a practice of 'following the knowledge agent'.

Roel Rutten and Frans Boekema take on this challenge by presenting the individual as the key learning agent in a regional context. Because individuals are 'spatially sticky', and attached to their spatial 'homes', learning process become anchored in a specific regional setting. To what extent this gives rise to processes of regional learning depends on the networks in which individuals interact. Spatial proximity may put a premium on interactive learning, and interaction may benefit from being embedded in a similar social-cultural environment. But networks evolve at very different spatial scales, and acquire very different qualities and outcomes in doing so. It is this spatiality of networks that determines the scope for regional learning, rather than the other way round. The authors see the following implication for the debate on innovation and space: 'Connecting the networks and innovation literature to the economic geography literature demands adding a spatial dimension to the former rather adding a network dimension to the latter' (Rutten and Boekema, this issue, p. ??).

In the final paper, Miranda Ebbekink and Arnoud Lagendijk present a new perspective on cluster policies. Starting point is the insight that proximity and embedding do not present automatic levers but elements of capacity-building for regional development. The key challenge for cluster initiatives, in particular, is to bridge the gap between policy aspirations and local business dynamics. This works in two ways. On the one hand, rather than simply copying allegedly successful cluster practicing from elsewhere, local policies should be adapted and tailored to the needs of cluster actors, notably firms. Different types of knowledge, from firms, research and experts, should be combined to create strategic intelligence and cluster visions. On the other, firms should be well informed about policy intentions and 
initiatives, and play a major role in its implementation. Such an associative practice serves to enhance 'policy leverage', to make sure that appropriate forms and combinations of policy interventions reach and support local research and business activities in an effective and efficient manner. This requires, the authors suggest, a new type of local communication, through what they call an 'Administrative Sensitisation Network' (ASN). They also assign a critical intermediary role to core agents operating at the interface of business and administration, the so-called civic entrepreneurs.

\section{References}

BATHELT H. and GLUCKLER J. (2003) Toward a relational economic geography J Econ Geogr 3(2), pp. 117-44. BOGGS J. S. and RANTISI N. M. (2003) The 'relational turn' in economic geography J Econ Geogr 3(2), pp. $109-16$.

BoschmA R. A. (2005) Proximity and innovation: A critical assessment Reg Stud 39(1), pp. 61-74.

CAPELLO R. and FAGGIAN A. (2005) Collective learning and relational capital in local innovation processes Reg Stud 39(1), pp. 75-87.

COOKE P. and MORGAN K. (1998) The associational economy: Firms, regions and innovation. Oxford: Oxford University Press.

MALECKI E. J. (1991) Technology and economic development. The dynamics of local, regional and national change. Harlow: Longman Scientific \& Technical.

MARTIN R. and SUNLEY P. (1998) Slow convergence? The new endogenous growth theory and regional development Econ Geogr 74(3), pp. 201-27.

MASKell P., BAthelt H. and MaLmberg A. (2006) Building global knowledge pipelines: The role of temporary clusters European Planning Studies 14(8), pp. 997-1013.

MASSEY D. (1994) Space, place and gender. Cambridge: Polity Press.

MASSEY D. (2005) For space. London: Sage.

MATTES J. (2011) Dimensions of proximity and knowledge bases: Innovation between spatial and nonspatial factors Reg Stud.

MoOdYSSON J. (2008) Principles and practices of knowledge creation: On the organization of "buzz" and "pipelines" in life science communities Econ Geogr 84(4), pp. 449-69.

STORPER M. (1997) The regional world. New York: Guildford Press.

VAN REINE P. P. and DANKBAAR B. (2011) The dynamic interaction between corporate and regional cultures: The case of southeast netherlands Tijdschr Econ Soc Ge 102(5), pp. 532-47.

Wolfe D. A. and GeRTLER M. S. (2004) Clusters from the inside and out: Local dynamics and global linkages Urban Studies 41(5-6), pp. 1071-93. 